\title{
Protein kinase CK2 is widely expressed in follicular, Burkitt and diffuse large B-cell lymphomas and propels malignant B-cell growth
}

\author{
Marco Pizzi ${ }^{1, *}$, Francesco Piazza2,3*, Claudio Agostinelli ${ }^{4}$, Fabio Fuligni ${ }^{4}$, Pietro \\ Benvenuti $^{1}$, Elisa Mandato ${ }^{2,3}$, Alessandro Casellato ${ }^{2,3}$, Massimo Rugge ${ }^{1}$, Gianpietro \\ Semenzato ${ }^{2,3}$ and Stefano A. Pileri ${ }^{4}$ \\ ${ }^{1}$ Department of Medicine, Surgical Pathology and Cytopathology Unit, DIMED University of Padua, Padua, Italy \\ 2 Department of Medicine, Hematology and Clinical Immunology Branch, DIMED University of Padua, Padua, Italy \\ ${ }^{3}$ Venetian Institute of Molecular Medicine (VIMM), Padua, Italy \\ ${ }^{4}$ Department of Experimental, Hematopathology and Hematology Sections, Diagnostic and Specialty Medicine, S. Orsola- \\ Malpighi Hospital, University of Bologna, Bologna, Italy \\ * These authors have contributed equally to this work
}

Correspondence to: Francesco Piazza, email: francesco.piazza@unipd.it

Keywords: CK2, Non-Hodgkin Lymphoma, CX-4945, B-cell

Received: January 11,2015 Accepted: January 28, 2015 Published: January 31, 2015

This is an open-access article distributed under the terms of the Creative Commons Attribution License, which permits unrestricted use, distribution, and reproduction in any medium, provided the original author and source are credited.

\section{ABSTRACT}

Serine-threonine kinase CK2 is highly expressed and pivotal for survival and proliferation in multiple myeloma, chronic lymphocytic leukemia and mantle cell Iymphoma. Here, we investigated the expression of a catalytic and $\beta$ regulatory CK2 subunits by immunohistochemistry in 57 follicular (FL), 18 Burkitt (BL), 52 diffuse large B-cell (DLBCL) non-Hodgkin lymphomas (NHL) and in normal reactive follicles. In silico evaluation of available Gene Expression Profile (GEP) data sets from patients and Western blot (WB) analysis in NHL cell-lines were also performed. Moreover, the novel, clinical-grade, ATP-competitive CK2-inhibitor CX-4945 (Silmitasertib) was assayed on lymphoma cells. CK2 was detected in $98.4 \%$ of cases with a trend towards a stronger CK2a immunostain in BL compared to FL and DLBCL. No significant differences were observed between Germinal Center B (GCB) and non-GCB DLBCL types. GEP data and WB confirmed elevated CK2 mRNA and protein levels as well as active phosphorylation of specific targets in NHL cells. CX-4945 caused a dosedependent growth-arresting effect on GCB, non-GCB DLBCL and BL cell-lines and it efficiently shut off phosphorylation of NF-KB RelA and CDC37 on CK2 target sites. Thus, CK2 is highly expressed and could represent a suitable therapeutic target in BL, FL and DLBCL NHL.

\section{INTRODUCTION}

Protein kinase CK2 is a tetrameric enzyme, composed by two catalytic ( $\alpha$ and/or $\alpha^{\prime}$ ) and two regulatory ( $\beta$ ) subunits. CK2 and its orthologs are highly conserved throughout evolution and are involved in the phosphorylation of hundreds of protein targets $(20 \%$ of human phosphoproteome) [1].

The wide spectrum of possible phosphorylation substrates justifies the pleiotropic roles of CK2 in cell biology. In vitro studies have demonstrated that CK2 is involved in cell cycle regulation, gene expression, protein translation, DNA repair and programmed cell-death [2]. CK2 is also known to be a master regulator of embryonic development, as it is involved in the mid-gestational morphogenesis of heart, brain, pharyngeal arch and somites $[3,4]$.

The central role of CK2 in several physiological processes is paralleled by its deregulation in many (solid and hematological) tumors [5, 6]. The over-expression of such kinase has indeed been documented in prostate, breast, lung, head and neck and colon carcinomas [7-13]. 
Table 1: CK2 $\alpha$ and CK2 $\beta$ expression in BL, FL and DLBCL.

\begin{tabular}{|c|c|c|c|c|c|c|c|c|c|}
\hline \multirow{2}{*}{ Lymphoma } & \multirow{2}{*}{$\begin{array}{c}\text { Type } \\
\text { (number) }\end{array}$} & \multicolumn{4}{|c|}{ CK2a } & \multicolumn{4}{|c|}{ CK2 $\beta$} \\
\hline & & 0 & $1+$ & $2+$ & $3+$ & $\mathbf{0}$ & $1+$ & $2+$ & $3+$ \\
\hline $\begin{array}{l}\text { Burkitt } \\
\text { (BL) }\end{array}$ & $\begin{array}{l}\text { Sporadic } \\
(18)\end{array}$ & $\begin{array}{c}0 \% \\
(0 / 18)\end{array}$ & $\begin{array}{l}5.6 \% \\
(1 / 18)\end{array}$ & $\begin{array}{l}61.1 \% \\
(11 / 18)\end{array}$ & $\begin{array}{l}33.3 \% \\
(6 / 18)\end{array}$ & $\begin{array}{c}0 \% \\
(0 / 18)\end{array}$ & $\begin{array}{l}11.1 \% \\
(2 / 18)\end{array}$ & $\begin{array}{l}55.6 \% \\
(10 / 18)\end{array}$ & $\begin{array}{l}33.3 \% \\
(6 / 18)\end{array}$ \\
\hline \multirow[t]{3}{*}{$\begin{array}{c}\text { Follicular } \\
\text { (FL) }\end{array}$} & Bcl2-positive (28) & $\begin{array}{c}0 \% \\
(0 / 28)\end{array}$ & $\begin{array}{l}14.3 \% \\
(4 / 28)\end{array}$ & $\begin{array}{l}46.4 \% \\
(13 / 28)\end{array}$ & $\begin{array}{l}39.3 \% \\
(11 / 28)\end{array}$ & $\begin{array}{c}0 \% \\
(0 / 28)\end{array}$ & $\begin{array}{l}14.3 \% \\
(4 / 28)\end{array}$ & $\begin{array}{l}42.9 \% \\
(12 / 28)\end{array}$ & $\begin{array}{l}42.9 \% \\
(12 / 28)\end{array}$ \\
\hline & Bcl2-negative (29) & $\begin{array}{c}0 \% \\
(0 / 29)\end{array}$ & $\begin{array}{l}13.8 \% \\
(4 / 29)\end{array}$ & $\begin{array}{l}58.6 \% \\
(17 / 29)\end{array}$ & $\begin{array}{l}27.6 \% \\
(8 / 29)\end{array}$ & $\begin{array}{c}0 \% \\
(0 / 29)\end{array}$ & $\begin{array}{l}13.8 \% \\
(4 / 29)\end{array}$ & $\begin{array}{l}69.0 \% \\
(20 / 29)\end{array}$ & $\begin{array}{l}17.2 \% \\
(5 / 29)\end{array}$ \\
\hline & $\begin{array}{c}\text { Total cases } \\
(57)\end{array}$ & $\begin{array}{c}0 \% \\
(0 / 57)\end{array}$ & $\begin{array}{l}14.0 \% \\
(8 / 57)\end{array}$ & $\begin{array}{l}52.6 \% \\
(30 / 57) \\
\end{array}$ & $\begin{array}{l}33.3 \% \\
(19 / 57) \\
\end{array}$ & $\begin{array}{c}0 \% \\
(0 / 57)\end{array}$ & $\begin{array}{l}14.0 \% \\
(8 / 57)\end{array}$ & $\begin{array}{l}56.1 \% \\
(32 / 57) \\
\end{array}$ & $\begin{array}{l}29.8 \% \\
(17 / 57) \\
\end{array}$ \\
\hline \multirow[t]{3}{*}{ DLBCL } & $\begin{array}{c}\text { GCB-type } \\
(30)\end{array}$ & $\begin{array}{l}3.3 \% \\
(1 / 30)\end{array}$ & $\begin{array}{l}10.0 \% \\
(3 / 30)\end{array}$ & $\begin{array}{l}73.3 \% \\
(22 / 30)\end{array}$ & $\begin{array}{l}13.3 \% \\
(4 / 30)\end{array}$ & $\begin{array}{l}3.3 \% \\
(1 / 30)\end{array}$ & $\begin{array}{l}6.7 \% \\
(2 / 30)\end{array}$ & $\begin{array}{l}73.3 \% \\
(22 / 30)\end{array}$ & $\begin{array}{l}16.7 \% \\
(5 / 30)\end{array}$ \\
\hline & $\begin{array}{c}\text { non GCB-type } \\
(22)\end{array}$ & $\begin{array}{l}4.5 \% \\
(1 / 22)\end{array}$ & $\begin{array}{l}4.5 \% \\
(1 / 22)\end{array}$ & $\begin{array}{l}59.1 \% \\
(13 / 22)\end{array}$ & $\begin{array}{l}31.8 \% \\
(7 / 22)\end{array}$ & $\begin{array}{l}4.5 \% \\
(1 / 22)\end{array}$ & $\begin{array}{l}4.5 \% \\
(1 / 22)\end{array}$ & $\begin{array}{c}72.7 \% \\
(16 / 22)\end{array}$ & $\begin{array}{l}18.2 \% \\
(4 / 22)\end{array}$ \\
\hline & $\begin{array}{c}\text { Total cases } \\
(52)\end{array}$ & $\begin{array}{l}3.8 \% \\
(2 / 52)\end{array}$ & $\begin{array}{l}7.7 \% \\
(4 / 52)\end{array}$ & $\begin{array}{l}67.3 \% \\
(35 / 52)\end{array}$ & $\begin{array}{l}21.2 \% \\
(11 / 52)\end{array}$ & $\begin{array}{l}3.8 \% \\
(2 / 52)\end{array}$ & $\begin{array}{l}5.8 \% \\
(3 / 52)\end{array}$ & $\begin{array}{l}73.1 \% \\
(38 / 52)\end{array}$ & $\begin{array}{l}17.3 \% \\
(9 / 52)\end{array}$ \\
\hline
\end{tabular}

Abbreviations. Non-GCB= non Germinal Center B-cell ; GCB= Germinal Center B-cell; DLBCL= Diffuse Large B-Cell Lymphoma.

In these tumors, CK2 up-regulation has been associated with increased tumor-cell survival and worse overall prognosis. Of note, treatment of cancer cells with CX4945 (Silmitasertib, a novel recently developed clinically grade ATP-competitive highly selective CK2-inhibitor) can induce a significant reduction of cell-growth and survival $[11,14,15]$. A common viewpoint on how CK2 sustains cancer cell growth relies on the "non oncogene addiction" process, whereby cancer cells exploit the advantages to keep up-regulated a critical "transversal" protein able to propel different oncogenic pathways [6].

Among lymphoproliferative disorders, CK2 overexpression has been reported in both precursor lymphoid (T-and B-Acute Lymphoblastic Leukemia) and mature B-cell neoplasms [5]. The latter encompass B-Chronic Lymphocytic Leukemia (B-CLL) [16, 17], Mantle Cell Lymphoma (MCL) [18] and Plasma Cell Myeloma (PCM) $[18,19]$. As for carcinoma cell-lines, in vitro and in vivo pre-clinical studies from our and other groups have indicated that first generation CK2 inhibitors as well as the newer CX-4945 have the potential to be novel therapeutic tools for the treatment of high CK2-expressing B cell tumors [16, 17, 20].

To fill a gap about to what extent is CK2 expressed in NHL and as to whether its inhibition could affect lymphoma cell viability, the present study evaluated CK2 mRNA and protein levels in the commonest forms of B-cell NHL: Follicular Lymphoma (FL), Diffuse Large B-Cell Lymphoma (DLBCL) and Burkitt Lymphoma (BL). CK2 protein expression was investigated by immunohistochemistry in a series of 127 formalinfixed paraffin-embedded (FFPE) biopsy samples. The obtained data were subsequently confirmed by checking CK2 mRNA levels from a repository of published cDNA microarray data available in the Oncomine database [21]. Immunohistochemical and molecular results were further validated by WB analysis on matched NHL cell-lines. To explore the effects and a possible therapeutic role for CK2 inactivation in the treatment of such lymphoid malignancies, CX-4945 was used in in vitro cell viability assays and $\mathrm{WB}$ analysis of the phosphorylation of CK2 target site on NF- $\mathrm{KB}$ RelA and CDC37, demonstrating that CX-4945 is highly effective in inducing cell growth arrest of GCB and non-GCB type DLBCL as well as BL cell lines and in inhibiting CK2 kinase activity directed towards pivotal signaling molecules.

\section{RESULTS}

\section{CK2 $\alpha$ and CK2 $\beta$ protein expression in primary NHL tissues}

Immunohistochemical analysis confirmed that in normal lymphoid tissue (tonsil) a moderate expression of CK $2 \alpha$ and CK2 $\beta$ is confined to the follicular area whereas only faint reactivity could be detected in the mantle zone (Figure S1 and [18]). Overall, 98.4\% (125/127) of the NHL cases analyzed disclosed some degree of CK2 expression (Figure 1, Table 1). Most of the lymphoma samples displayed high nuclear/cytoplasmic protein expression. In particular, a moderate to strong positivity (high-expression group: score $\geq 2+$ ) was documented in more than $88 \%$ of cases (CK2 $\alpha$ and CK2 $\beta$ score $\geq 2+$ : $88.2 \%(112 / 127)$ for both subunits) (details in Figure S2).

Compared to FL and DLBCL, BL was more frequently associated with moderate-to-strong CK2 $\alpha$ expression (trend of association, Fisher's exact test). In particular, CK2 $\alpha$ score $\geq 2+$ was recorded in $94.4 \%(17 / 18)$ of BLs and in $86.0 \%(49 / 57)$ and $88.5 \%(46 / 52)$ of FLs and DLBCLs, respectively. Less marked differences were 


\begin{tabular}{|c|c|c|c|c|c|c|c|c|}
\hline Table 2: CK2 $\alpha$ and CK2 $\beta$ expression by FL grade. \\
\hline Follicular Lymphoma & \multicolumn{7}{|c|}{ CK2 $\alpha$} & \multicolumn{4}{|c|}{ CK2 $\beta$} \\
\cline { 2 - 9 } Grade & 0 & $1+$ & $2+$ & $3+$ & 0 & $1+$ & $2+$ & $3+$ \\
\hline Grade 1 & 0 & $2 / 13$ & $7 / 13$ & $4 / 13$ & 0 & $2 / 13$ & $7 / 13$ & $4 / 13$ \\
$(13$ cases $)$ & $(-)$ & $(15.4 \%)$ & $(53.8 \%)$ & $(30.8 \%)$ & $(-)$ & $(15.4 \%)$ & $(53.8 \%)$ & $(30.8 \%)$ \\
\hline Grade 2 & 0 & $3 / 26$ & $13 / 26$ & $10 / 26$ & 0 & $3 / 26$ & $14 / 26$ & $9 / 26$ \\
$(26$ cases $)$ & $(-)$ & $(11.5 \%)$ & $(50.0 \%)$ & $(38.5 \%)$ & $(-)$ & $(11.5 \%)$ & $(53.8 \%)$ & $(34.6 \%)$ \\
\hline Grade 3 & 0 & $3 / 18$ & $10 / 18$ & $5 / 18$ & 0 & $3 / 18$ & $11 / 18$ & $4 / 18$ \\
$(18$ cases $)$ & $(-)$ & $(16.7 \%)$ & $(55.6 \%)$ & $(27.8 \%)$ & $(-)$ & $(16.7 \%)$ & $(61.1 \%)$ & $(22.2 \%)$ \\
\hline Total & 0 & $8 / 57$ & $30 / 57$ & $19 / 57$ & 0 & $8 / 57$ & $32 / 57$ & $17 / 57$ \\
& $(-)$ & $(14.0 \%)$ & $(52.6 \%)$ & $(33.3 \%)$ & $(-)$ & $(14.0 \%)$ & $(56.1 \%)$ & $(29.8 \%)$ \\
\hline
\end{tabular}

observed in CK2 $\beta$ expression patterns (Table 1).

As for DLBCL, CK2 subunits were moderately-tostrongly expressed in both GCB and non-GCB subtypes [CK2 $\alpha$ score $\geq 2+: 90.9 \%(20 / 22)$ of non-GCB DLBCL and $86.7 \%(26 / 30)$ of GCB-DLBCL; CK2 $\beta$ score $\geq 2+$ : $90.9 \%(20 / 22)$ of non-GCB DLBCL and $90.0 \%(27 / 30)$ of GCB-DLBCL; no statistically significant differences, Fisher's exact test; Table 1].

CK2 subunits were equally expressed in Bcl2positive and Bcl2-negative FL. In particular, moderate-tostrong positivity for CK2 $\alpha$ was recorded in $85.7 \%(24 / 28)$ of Bcl2-positive and in $86.2 \%(25 / 29)$ of Bcl2-negative FL (no statistically significant differences, Fisher's exact test). Similar results were obtained for the CK2 $\beta$ subunit (Table 1). No significant differences in CK2 expression were recorded among FL of different grades (Table 2).

\section{GEP analysis of CK2 mRNA expression in NHL}

To evaluate whether differences in CK2 protein expression were also present at the mRNA level, the mRNA signatures of both catalytic (CSNK2A1 and $C S N K 2 A 2)$ and regulatory (CSNK2B) subunits were assessed, by checking available gene expression profiles (GEP) data sets in the Oncomine database [21]. GEP of the available study [22] confirmed the trend of the immunohistochemical results, with high CSNK2A1, CSNK2A2 and CSNK2B mRNA levels in all the considered lymphoid tumors. In particular, BL featured higher CSNK2A1 and CSNK2A2 expression compared to both FL and DLBCL (Student's $t$-test; $\mathrm{p}<0.001$ ). The same results were obtained for CSNK2B (Student's $t$-test; $\mathrm{p}<0.001$ ) (Figure 2). Differences in the mRNA signatures of FL and DLBCL were not statistically relevant.

\section{WB analysis of CK2 protein expression in NHL cell lines}

To further confirm these findings, we performed WB analysis of CK $2 \alpha$ and CK2 $\beta$ expression in BL and DLBCL cell-lines. Peripheral CD19-positive B-cells from healthy donors were used as controls (Figure 3). WB analysis confirmed CK2 $\alpha$ and CK2 $\beta$ over-expression in all the examined DLBCL and BL lines, with much higher protein levels than in normal B-lymphocytes. Importantly, WB also documented CK2 $\beta$ Ser209-phosphorylation, which is a mark of CK2 activation by Cdc2/CyclinB kinase [23], in all the cell-lines. Moreover, the presence of a phosphorylated CK2-target such as Ser13 on the HSP90cochaperone $\mathrm{CDC} 37$ [24, 25] in all the examined cell-lines

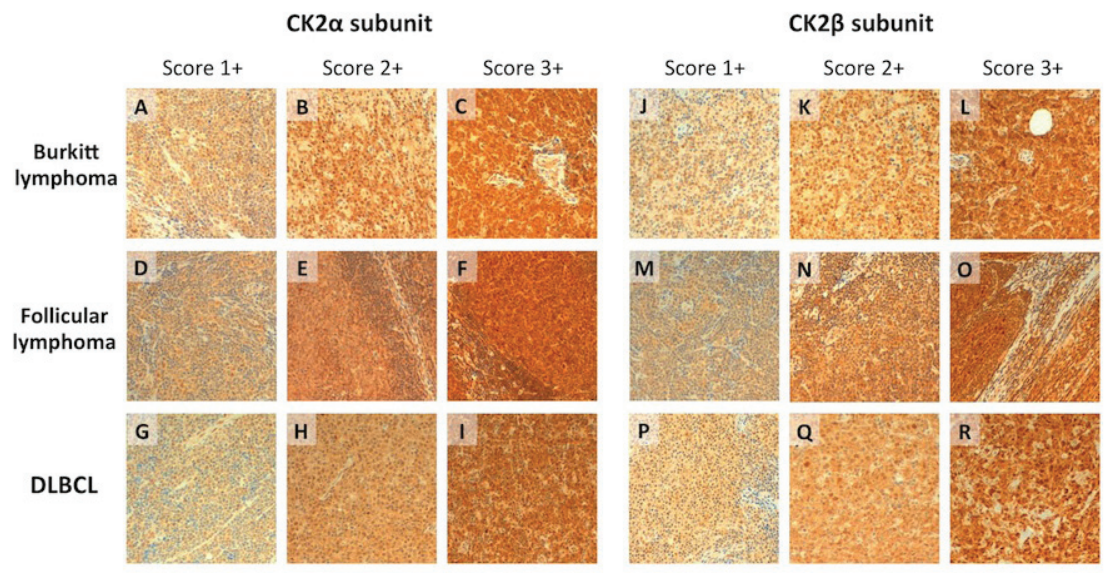

Figure 1: CK2 $\alpha$ and CK2 $\beta$ expression by immunohistochemistry in FL, BLand DLBCL. Representative immunohistochemical features of the considered lymphoproliferative lesions. Both BL (A-C; J-L), FL (D-F; M-O), and DLBCL (G-I; P-R) displayed consistent positivity for the regulatory and catalytic CK2 subunits. In all the considered lymphoma subtypes, variable immunohistochemical positivity (from score $1+$ to score +3 ) was observed (H\&E and immunoperoxidase stain; original magnification, $\mathrm{x} 20$ ). 
provided clear evidence that CK2 is also functionally active in DLBCL and BL cells (Figure 3).

\section{Effects of CK2 inhibition with CX4945 on NHL cell line survival and viability}

We finally tested if CK2 could be a suitable target for harming B-cell lymphoma growth. Non-GCB type DLBCL cell-line Oci Ly10, GCB type DLBCL cell-line Oci Ly19 as well as normal peripheral blood mononuclear cells (PBMC, controls) were cultured in the presence of increasing concentrations of CX-4945 $(2.5,5$ and $10 \mu \mathrm{M})$ and the amount of apoptosis was then measured after 24 hours by Annexin V staining and fluorescence activated cell sorting (FACS) analysis. Remarkably, while DLBCL cell-lines of both subtypes displayed a dose-dependent induction of apoptosis, PBMC from healthy donors were substantially spared by CX-4945 at the used concentrations (Figure 4A). Furthermore, cell proliferation/viability, as evaluated by the MTT (3-(4,5-dimethylthiazol-2-yl)-2,5diphenyl tetrazolium bromide) assay, demonstrated that non-GCB (Figure 4B), GCB (Figure 4C) DLBCL celllines as well as BL Raji cells (Figure 4D) were sensitive - even though to a different extent - to the growth-arresting effect induced by CX-4945, in a dose-dependent fashion.
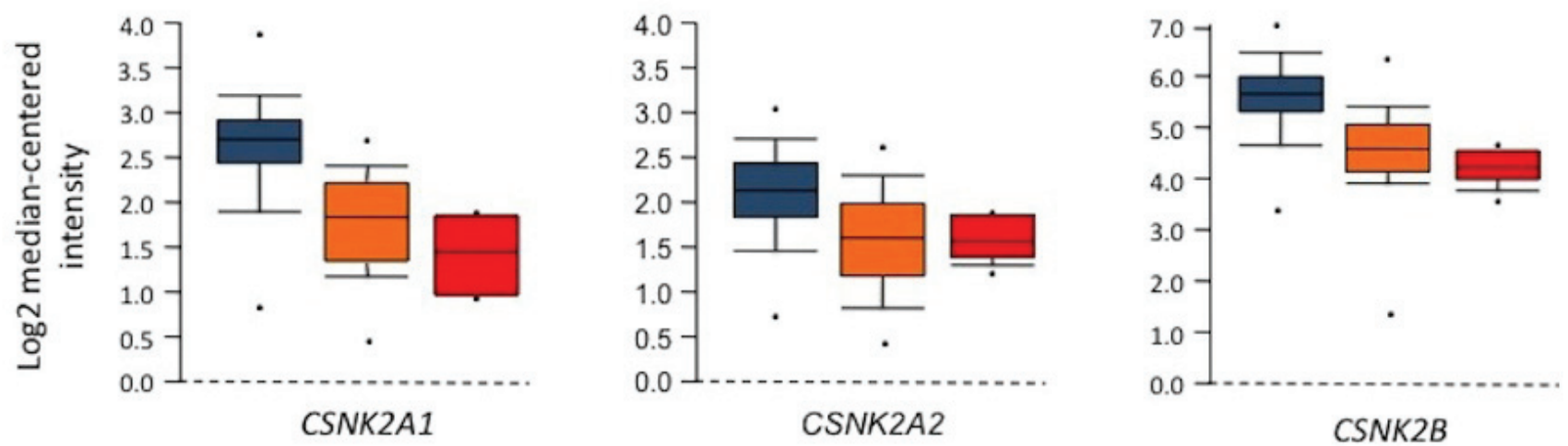

Figure 2: Gene expression data for CK2 subunits in FL, BL and DLBCL. CSNK2A1, CSNK2A2 and CSNK2B mRNA expression levels from Basso et al. data set are considered [22]. Box plots show consistent mRNA expression in BL (light blu), DLBCL (yellow) and FL (red), with significantly higher mRNA levels in BL compared to both DLBCL and FL (CSNK2A1 expression data: BL versus DLBCL: $\mathrm{t}$ test, $\mathrm{P}=7.32 \mathrm{E}-12$; $\mathrm{BL}$ versus $\mathrm{FL}$ : $\mathrm{t}$ test, $\mathrm{P}=0.00038$; DLBCL versus $\mathrm{FL}$ : $\mathrm{t}$ test, $\mathrm{P}=0.07449$; CSNK2A2 expression data: $\mathrm{BL}$ versus $\mathrm{DLBCL}$ : $\mathrm{t}$ test, $\mathrm{P}=1.41 \mathrm{E}-7$; $\mathrm{BL}$ versus $\mathrm{FL}$ : $\mathrm{t}$ test, $\mathrm{P}=0.0002$; $\mathrm{DLBCL}$ versus $\mathrm{FL}$ : $\mathrm{t}$ test, $\mathrm{P}=0.78113$; CSNK2B expression data: $\mathrm{BL}$ versus $\mathrm{DLBCL}$ : $\mathrm{t}$ test, $\mathrm{P}=3.06 \mathrm{E}-9$; $\mathrm{BL}$ versus $\mathrm{FL}$ : $\mathrm{t}$ test, $\mathrm{P}=3.71 \mathrm{E}-6$; DLBCL versus $\mathrm{FL}: \mathrm{t}$ test, $\mathrm{P}=0.03349$ ).

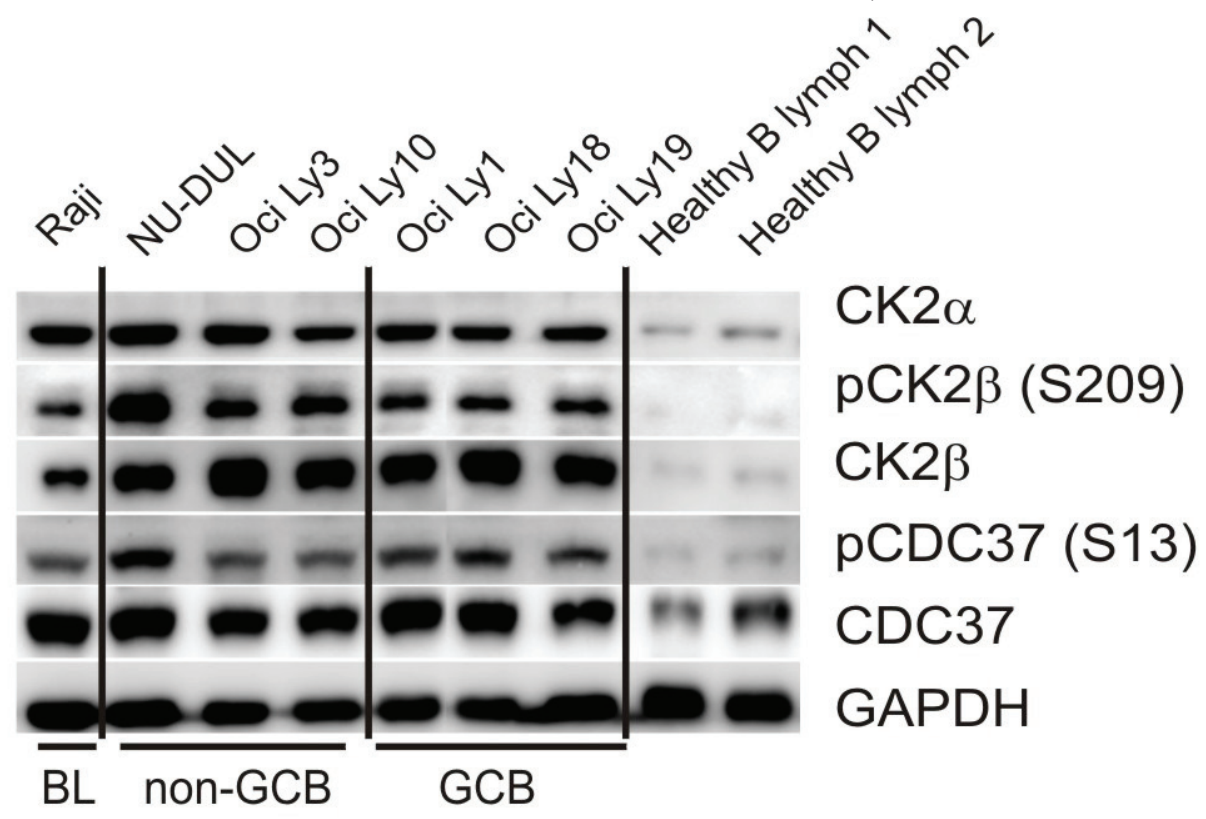

Figure 3: WB assays for CK2 expression in lymphoma cell-lines and normal B-cells. Expression of CK2 $\alpha$, CK2 $\beta$, CK2 $\beta$ phosphorylation on Ser209, total CDC37, CDC37 phosphorylation on Ser13 in BL (Raji), non-GCB type DLBCL (NU-DUL, Oci Ly 3 and Oci Ly 10) and GCB type DLBCL (Oci Ly 1, Oci Ly 18 and Oci Ly 19) cell-lines. Normal B lymphocytes (1 and 2) isolated from buffy coat of healthy donors were used as controls. 
Of note, WB analysis revealed a marked down modulation of the phosphorylation status of two CK2-specific target sites, namely Ser529 on the NF- $\kappa$ B subunit p65/RelA [26] and Ser13 on the co-chaperone CDC37, in Raji, Oci Ly 10 and Oci Ly 19 cell lines, after treatment for three hours with $5 \mu \mathrm{M}$ CX-4945 (Figure 4E).

\section{DISCUSSION}

NHL are a composite group of B-cell lymphoproliferative disorders, encompassing both indolent and aggressive tumors [27, 28]. Despite the pathobiological and clinical features of such lymphomas have been thoroughly investigated, prognosis and therapeutic outcomes remain highly variable and the search for novel therapeutic targets is still eagerly ongoing [29-31]. The recent development of protein kinase CK2 inhibitors as anti-cancer agents $[15,32,33]$ and the evidence of CK2-expression in lymphocytes of reactive germinal centers (this paper and [18]) prompted us to investigate CK2 in a large series of FLs, DLBCLs and BLs.

Our results clearly demonstrate that CK2 is widely expressed in the vast majority of the commonest subtypes of NHL. Of note, immunohistochemical and cDNA arrays analyses indicate a trend for $\mathrm{BL}$ as associated with higher CK2 protein levels compared to both FL and DLBCL (Figure 1 and Figure 2). These data achieved on patients specimens were further sustained by in vitro assays on BL and DLBCL cell-lines. In particular, WB analysis revealed constitutive $\mathrm{CK} 2 \alpha$ and $\mathrm{CK} 2 \beta$ expression in all the lymphoma cell-lines used, with more abundant protein levels than in normal B-lymphocytes (Figure 3). WB also provided hints about the functional status of CK2. The detection of CK $2 \beta$ phosphorylation on Ser209 may indeed be regarded as a compelling readout of $\mathrm{CK} 2$ activation by the Cdc2/CyclinB complex, a feature likely to be linked to high cell proliferative activity [23]. In addition, we detected the presence of a known specific phosphorylated target of CK2 (phospho-Ser13 on CDC37) in lymphoma
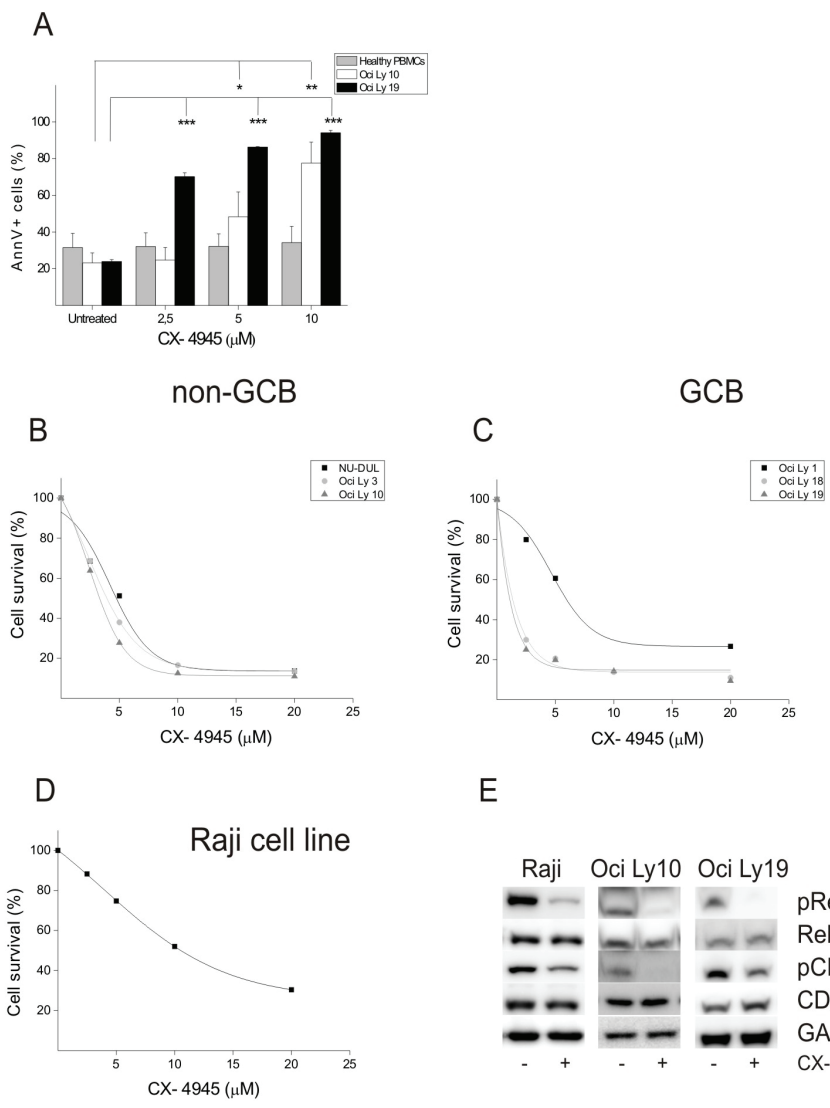

E

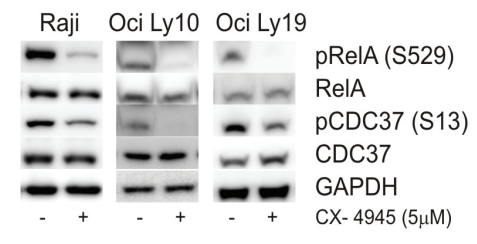

Figure 4: Cell viability assays on BL and DLBCL cell-lines. (A) Graph summarizing the percentage of Annexin V-positive cells resulting upon exposure of healthy peripheral blood mononuclear cells (PBMC, gray bars), non-GCB type DLBCL cell line Oci Ly10 (white bars) and GCB type DLBCL cell line Oci Ly 19 (black bars) to mock (untreated) or to increasing concentrations of the CK2-selective inhibitor CX-4945. (B) MTT assay on non-GCB type DLBCL cell-lines NU-DUL, Oci Ly 3, Oci Ly 10 exposed for 48 hours to mock (100\% of survival) or increasing concentrations of CX-4945. (C) and (D) Same as in B for GCB type DLBCL cell-lines Oci Ly 1, Oci Ly 18, Oci Ly 19 (C) and BL cell-line Raji (D). (E) WB analysis of the expression of total and phosphorylated CK2 specific targets RelA and CDC37 in BL (Raji), non-GCB type (Oci Ly10) and GCB type (Oci Ly 19) DLBCL cell lines after treatment for 3 hours with CX-4945 at $5 \mu \mathrm{M}$ concentration. 
cells, which provides further evidence of CK2 active status as compared to normal B cells. Interestingly, Ser13phosphorylated $\mathrm{CDC} 37$ is a critical co-chaperone of HSP90, which has been clearly shown to be essential for proper folding of HSP90 client oncogenic kinases [34]. To note, CK2 mRNA and protein levels do not follow a perfectly identical trend, since we observed less marked differences in the expression of $\mathrm{CK} 2$ protein compared to mRNA across the different NHL subtypes. This could be due to various possibilities, for instance to the fact that the transcription of CK2 mRNAs is differently regulated in $\mathrm{BL}$ as compared to FL and DLBCL because of different sets of transcription factors. Also, regardless the mRNA levels, the CK2 subunits could be post-translationally controlled in neoplastic B cells, causing their differential levels within NHL subtypes. Further work will elucidate this aspect.

From a practical viewpoint, the widespread expression of CK2 limits its applicability to the routine histopathological diagnosis of B-cell lymphomas. On the other hand, the high levels and the constitutive activation of CK2 pinpoint such kinase as an additional potential target for the treatment of FL, DLBCL and BL. This hypothesis, at least for DLBCL and BL, is sustained by the results of cell viability assays after incubation with the CK2-inhibitor, CX-4945 (Figure 4). In such assays, lymphoma cell-lines demonstrated a dose- and timedependent response to CX-4945. Remarkably, CX-4945 efficacy was supported by a clear down modulation of phospho Ser529 RelA and phospho Ser13 CDC37, two well-known CK2 targets. Regarding this latter molecule, since it is an essential co-chaperone of HSP90, it will be interesting to test whether double targeting of HSP90 and CK2 would be synergic in causing NHL cell death, similarly as in MM cells, like we recently demonstrated in in vivo and in vitro models [20].

In conclusion, our work suggests that further investigations on the pre-clinical and clinical applications of CK2-inhibitors against DLBCL, BL and possibly FL are worth pursuing. It also point to the rationale of performing parallel studies on the role of CK2-regulated networks in B-cell physiology and in B-cell tumor pathogenesis.

\section{MATERIALS AND METHODS}

\section{Tissue samples}

Cases were retrospectively collected from the archives of the Hematopathology Section, Sant' OrsolaMalpighi Hospital (University of Bologna, Bologna, Italy). Overall, 127 NHLs were considered: (i) 18 cases of sporadic BL; (ii) 52 cases of DLBCL (30 cases of GCBtype and 22 cases of non-GCB type, as sub-classified according to Hans' algorithm [35]); (iii) 57 cases of FL
(28 cases of Bcl2-positive FL; 29 cases of Bcl2-negative FL). The present series was enriched in Bcl2-negative FLs to specifically investigate possible differences in CK2-expression between Bcl2-positive and Bcl2-negative cases. Distribution of FLs according to the histological grade was as follows: (i) 13 cases of Grade 1 FL (Bcl2positive: 6 cases; Bcl2-negative: 7 cases); (ii) 26 cases of Grade 2 FL (Bcl2-positive: 12 cases; Bcl2-negative: 14 cases); (iii) 18 cases of Grade 3 FL (Bcl2-positive: 10 cases; Bcl2-negative: 8 cases; all cases were Grade 3A).

For each lymphoma subtype, tissue microarray (TMA) blocks were prepared, obtaining three tissue cores from each original sample. Adequate positive (lymphoid and thymic tissue) and negative (myocardium) controls were also included.

None of the patients received radiation therapy or chemotherapy prior to biopsy sampling and histological evaluation. The institutional and international (Declaration of Helsinki) ethics regulations governing research conducted on human tissues were followed, and all patients gave their informed consent.

\section{Immunohistochemical analysis}

Immunohistochemistry was performed on $4 \mu \mathrm{m}$ thick FFPE sections, using CK2 $\alpha$ (EP1963Y, Epitomics, CA, USA) and CK2 $\beta$ (6D5, Santa Cruz Biotechnology, CA, USA) monoclonal antibodies. Heat/EDTA-based antigen retrieval methods were applied, as previously described $[18,36]$. Antigen detection was performed with the Bond Polymer Refine Detection kit in an automated immunostainer (Bond maX, Menarini, Italy) [18].

$\mathrm{CK} 2 \alpha$ and $\mathrm{CK} 2 \beta$ immunostain was semiquantitatively scored in a four-tiered scale, as follows: score $0=$ negative staining; score $1+=$ weak positivity or positive staining in $<5 \%$ of tumor cells; score $2+=$ moderate positivity or strong positive staining in $<50 \%$ of cells; score $3+=$ strong positive staining in $>50 \%$ of tumor cells. Immunohistochemical reactions were independently scored by two investigators (MP and PB; agreement $\mathrm{k}>0.8$ ). In case of discrepancies, a consensus opinion was rendered. For the statistical interpretation of immunohistochemical data, scores $0 / 1+$ and $2+/ 3+$ were lumped in "low-expression" and "high-expression" groups, respectively.

\section{cDNA microarray analysis}

The Oncomine database and gene microarray analysis tool, a repository for published cDNA microarray data (http://www.oncomine.org) [21] was explored (on September-November 2014) for CK2 $\alpha$, CK2 $\alpha$ ' and CK2 $\beta$ mRNA expression (searched genes: CSNK2A1, $C S N K 2 A 2$ and $C S N K 2 B$, respectively). Only studies assessing gene expression profiling of BL, FL and DLBCL 
were considered. Studies considering $\leq 5$ cases for each lymphoma entity were excluded. Of the publicly available data sets, one met such inclusion criteria [22].

\section{Chemicals}

CX-4945 was purchased from Activate-Scientific $\mathrm{GmbH}$, Germany. The specificity and mechanism of action of this inhibitor were previously characterized [18, 37].

\section{Cell cultures and healthy controls' cells}

Non-GCB type DLBCL cell-line NU-DUL and GCB type DLBCL cell-lines OCI Ly1 and OCI Ly18 were purchased from the Deutsche Sammlung von Mikroorganismen und Zellkulturen (DSMZ, Germany). Non-GCB type DLBCL cell-lines OCI Ly3, OCI Ly10 and GCB type DLBCL cell-line OCI Ly19 were a kind gift of Dr. F. Bertoni, Bellinzona, Switzerland. NU-DUL were maintained in RPMI 1640 medium supplemented with $15 \%$ fetal bovine serum (FCS) + 2-Mercaptoethanol (50mM; Invitrogen); OCI Ly10, OCI Ly3 and OCI Ly1 in IMDM 20\% FCS + 2-Mercaptoethanol (50mM); OCI Ly18 in RPMI 10\% FCS + 2-Mercaptoethanol (50mM) and OCI Ly19 in RPMI 10\% + 2-Mercaptoethanol $(50 \mathrm{mM})+$ MEM NEAA + sodium pyruvate. BL Raji cellline was purchased from ATCC and cultured in RPMI $20 \%$ FCS. Testing for Mycoplasma infection was carried at a monthly basis. Peripheral blood mononuclear cells (PBMCs) and B lymphocytes from healthy donors were obtained from peripheral blood as per standard Ficoll Paque $^{\circledR}$ protocol; B lymphocytes were purified using CD19-coated magnetic MicroBeads according to the manufacturer's protocol (Miltenyi Biotech).

\section{WB and antibodies}

Whole cell extracts (WCE) were obtained by lysis with $20 \mathrm{mM}$ Tris (pH 7.5), $150 \mathrm{mM} \mathrm{NaCl}, 2$ mM EDTA, 2 mM EGTA supplemented with 0,5\% Triton X-100 (SigmaAldrich), protease inhibitor cocktail (Sigma-Aldrich), phosphatase inhibitor cocktail (Thermo Scientific), $1 \mathrm{mM}$ phenyl-methyl-sulfonyl fluoride (PMSF; Sigma-Aldrich), $1 \mu \mathrm{M}$ okadaic acid (Sigma-Aldrich), dithiothreitol (DTT; Fluka). Twenty to $50 \mu \mathrm{g}$ of WCE were subjected to SDS-PAGE, transferred to PVDF membranes and immunoblotted with the following primary antibodies: anti-CK $2 \alpha$ (kindly provided by Dr S. Sarno, University of Padua, Italy); anti-CDC37 (Santa Cruz Biotechnology, Santa Cruz, CA) anti-phospho-Ser13 CDC37 (Abcam); anti-CK2 $\beta$ (BD Biosciences, USA); anti-phospho-Ser209 CK2 $\beta$ (Assay Biotech) and anti-GAPDH (Ambion); antiRelA (Abcam) and anti-phospho-Ser529 RelA (Santa Cruz Biotechnology, Santa Cruz, CA). As secondary antibodies: anti-rabbit IgG HRP-linked antibody (Cell Signaling, Beverly, MA); HRP labeled goat anti-mouse IgG (KPL, Gaithersburg, MD, USA). Detection was performed using ECL (Pierce, Thermo Scientific), LiteAblot Extend Long Lasting Chemiluminescent Substrate (Euroclone) or LiteAblot Turbo Extra Sensitive Chemiluminescent Substrate (Euroclone) according to manufacturer's instructions.

\section{Determination of apoptosis}

Apoptosis was assessed by Annexin V/Propidium Iodide staining according to the manufacturers' instructions (BD Pharmingen). After 24 hours of treatment cells were labeled with FITC-conjugated Annexin V and Propidium Iodide (Becton-Dickinson, Italy). Fluorescence Activated Cell Sorting (FACS) analysis was performed using a FACS-Canto Cell Cytometer and the CellQuest software (Becton-Dickinson, Italy).

\section{MTT assay}

MTT (3-(4,5-dimethylthiazol-2-yl)-2,5-diphenyl tetrazolium bromide) assay was performed in 96-well plates using a CellTiter $96^{\circledR}$ kit (Promega). Briefly, $0.5 \mathrm{x}$ $10^{4}$ cells were plated in 96-well plates the day before the experiment. At the end of the treatment with CX-4945 (48 hours), culture medium was removed and replaced with $100 \mathrm{ml}$ of complete medium without phenol red +50 $\mathrm{ml}$ of MTT to each well. During an incubation period of 1.5 hour at $37^{\circ} \mathrm{C}$, the MTT salt is metabolically reduced only by viable cells into an insoluble coloured formazan; the absorbance/optical density was read and reported by a microplate reader at $570 \mathrm{~nm}$. Values are expressed as percentage of viable cells compared with untreated cells, considered as $100 \%$. This assay was performed in parallel with all cell experiments to exclude any artefact resulting from differences in cell viability.

\section{Statistical analysis}

Data were evaluated for their statistical significance with the two-tail paired Student's t test and differences and correlations between groups were tested by applying analysis of variance (ANOVA) or the Fisher's exact test (immunohistochemical results). Pearson's product moment correlation test was also adopted in a specific analysis. $P$ values below 0.05 were considered statistically significant.

\section{ACKNOWLEDGEMENTS}

This work was supported by grants from Associazione Italiana per la Ricerca sul Cancro (AIRC) n. 14481 to F.P. and n. 10007 to S.A.P. ("5 x mille"), from 
the Italian Ministry of Education, University and Research (FIRB - Futuro in Ricerca 2008, n. RBFR086EW9_001) to F.P., from the University of Padova (Progetti di Ricerca di Ateneo n. CPDA114940/11) to F.P.

\section{Authorship contributions}

M.P., C.A., F.F., P.B., E.M, A.C. collected data and performed the analysis. M.R., G.S. and S.A.P. provided availability to samples, directed the research, gave funding and suggestions. F.P. conceived and designed the study, provided funding and wrote the manuscript.

\section{DISCLOSURE OF CONFLICTS OF INTEREST}

None of the authors has a conflict of interest with this work.

\section{Editorial note}

This paper has been accepted based in part on peerreview conducted by another journal and the authors' response and revisions as well as expedited peer-review in Oncotarget.

\section{REFERENCES}

1. Litchfield DW. Protein kinase CK2: structure, regulation and role in cellular decisions of life and death. Biochem J. 2003; 369(Pt 1):1-15.

2. Meggio F and Pinna LA. One-thousand-and-one substrates of protein kinase CK2? FASEB journal : official publication of the Federation of American Societies for Experimental Biology. 2003; 17(3):349-368.

3. Buchou T, Vernet M, Blond O, Jensen HH, Pointu H, Olsen BB, Cochet C, Issinger OG and Boldyreff B. Disruption of the regulatory beta subunit of protein kinase $\mathrm{CK} 2$ in mice leads to a cell-autonomous defect and early embryonic lethality. Mol Cell Biol. 2003; 23(3):908-915.

4. Lou DY, Dominguez I, Toselli P, Landesman-Bollag E, O'Brien C and Seldin DC. The alpha catalytic subunit of protein kinase CK2 is required for mouse embryonic development. Mol Cell Biol. 2008; 28(1):131-139.

5. Piazza F, Manni S, Ruzzene M, Pinna LA, Gurrieri C and Semenzato G. Protein kinase CK2 in hematologic malignancies: reliance on a pivotal cell survival regulator by oncogenic signaling pathways. Leukemia. 2012; 26(6):1174-1179.

6. Ruzzene M and Pinna LA. Addiction to protein kinase CK2: a common denominator of diverse cancer cells? Biochim Biophys Acta. 2010; 1804(3):499-504.

7. Wang G, Ahmad KA, Unger G, Slaton JW and Ahmed K.
CK2 signaling in androgen-dependent and -independent prostate cancer. J Cell Biochem. 2006; 99(2):382-391.

8. Giusiano S, Cochet C, Filhol O, Duchemin-Pelletier E, Secq V, Bonnier P, Carcopino X, Boubli L, Birnbaum D, Garcia $\mathrm{S}$, Iovanna $\mathrm{J}$ and Charpin C. Protein kinase CK2alpha subunit over-expression correlates with metastatic risk in breast carcinomas: quantitative immunohistochemistry in tissue microarrays. Eur J Cancer. 2011; 47(5):792-801.

9. Gray GK, McFarland BC, Rowse AL, Gibson SA and Benveniste EN. Therapeutic CK2 inhibition attenuates diverse prosurvival signaling cascades and decreases cell viability in human breast cancer cells. Oncotarget. 2014; 5(15):6484-6496.

10. Scaglioni PP, Yung TM, Choi S, Baldini C, Konstantinidou $G$ and Pandolfi PP. CK2 mediates phosphorylation and ubiquitin-mediated degradation of the PML tumor suppressor. Mol Cell Biochem. 2008; 316(1-2):149-154.

11. Bliesath J, Huser N, Omori M, Bunag D, Proffitt C, Streiner N, Ho C, Siddiqui-Jain A, O'Brien SE, Lim JK, Ryckman DM, Anderes K, Rice WG and Drygin D. Combined inhibition of EGFR and CK2 augments the attenuation of PI3K-Akt-mTOR signaling and the killing of cancer cells. Cancer Lett. 2012; 322(1):113-118.

12. $\mathrm{Yu} \mathrm{M}$, Yeh $\mathrm{J}$ and Van Waes C. Protein kinase casein kinase 2 mediates inhibitor-kappaB kinase and aberrant nuclear factor-kappaB activation by serum factor(s) in head and neck squamous carcinoma cells. Cancer Res. 2006; 66(13):6722-6731.

13. Izeradjene K, Douglas L, Delaney A and Houghton JA. Casein kinase II (CK2) enhances death-inducing signaling complex (DISC) activity in TRAIL-induced apoptosis in human colon carcinoma cell lines. Oncogene. 2005; 24(12):2050-2058.

14. Ho C, Rice R, Drygin D, Bliesath J, Streiner N, SiddiquiJain A, Proffitt C, O'Brien SE and Anderes K. CX-4945, a selective and orally bioavailable inhibitor of protein kinase CK2 inhibits PI3K/Akt, JAK-STAT and NF-kB signaling and induces apoptosis in multiple myeloma cells. Blood (ASH annual meeting abstracts). 2010; 116:787.

15. Siddiqui-Jain A, Drygin D, Streiner N, Chua P, Pierre F, O'Brien SE, Bliesath J, Omori M, Huser N, Ho C, Proffitt C, Schwaebe MK, Ryckman DM, Rice WG and Anderes K. CX-4945, an orally bioavailable selective inhibitor of protein kinase CK2, inhibits prosurvival and angiogenic signaling and exhibits antitumor efficacy. Cancer Res. 2010; 70(24):10288-10298.

16. Martins LR, Lucio P, Silva MC, Anderes KL, Gameiro P, Silva MG and Barata JT. Targeting CK2 overexpression and hyperactivation as a novel therapeutic tool in chronic lymphocytic leukemia. Blood. 2010; 116(15):2724-2731.

17. Prins RC, Burke RT, Tyner JW, Druker BJ, Loriaux MM and Spurgeon SE. CX-4945, a selective inhibitor of casein kinase-2 (CK2), exhibits anti-tumor activity in hematologic malignancies including enhanced activity in chronic lymphocytic leukemia when combined with fludarabine and 
inhibitors of the B-cell receptor pathway. Leukemia. 2013; 27(10):2094-2096.

18. Manni S, Brancalion A, Mandato E, Tubi LQ, Colpo A, Pizzi M, Cappellesso R, Zaffino F, Di Maggio SA, Cabrelle A, Marino F, Zambello R, Trentin L, Adami F, Gurrieri C, Semenzato $G$, et al. Protein kinase CK2 inhibition down modulates the NF-kappaB and STAT3 survival pathways, enhances the cellular proteotoxic stress and synergistically boosts the cytotoxic effect of bortezomib on multiple myeloma and mantle cell lymphoma cells. PLoS One. 2013; 8(9):e75280.

19. Piazza FA, Ruzzene M, Gurrieri C, Montini B, Bonanni L, Chioetto G, Di Maira G, Barbon F, Cabrelle A, Zambello R, Adami F, Trentin L, Pinna LA and Semenzato G. Multiple myeloma cell survival relies on high activity of protein kinase CK2. Blood. 2006; 108(5):1698-1707.

20. Manni S, Brancalion A, Tubi LQ, Colpo A, Pavan L, Cabrelle A, Ave E, Zaffino F, Di Maira G, Ruzzene M, Adami F, Zambello R, Pitari MR, Tassone P, Pinna LA, Gurrieri C, et al. Protein Kinase CK2 Protects Multiple Myeloma Cells from ER Stress-Induced Apoptosis and from the Cytotoxic Effect of HSP90 Inhibition through Regulation of the Unfolded Protein Response. Clinical cancer research. 2012; 18(7):1888-1900.

21. Rhodes DR, Yu J, Shanker K, Deshpande N, Varambally R, Ghosh D, Barrette T, Pandey A and Chinnaiyan AM. ONCOMINE: a cancer microarray database and integrated data-mining platform. Neoplasia. 2004; 6(1):1-6.

22. Basso K, Liso A, Tiacci E, Benedetti R, Pulsoni A, Foa R, Di Raimondo F, Ambrosetti A, Califano A, Klein U, Dalla Favera R and Falini B. Gene expression profiling of hairy cell leukemia reveals a phenotype related to memory $\mathrm{B}$ cells with altered expression of chemokine and adhesion receptors. The Journal of experimental medicine. 2004; 199(1):59-68.

23. Meggio F, Boldyreff B, Marin O, Issinger OG and Pinna LA. Phosphorylation and activation of protein kinase CK2 by $\mathrm{p} 34 \mathrm{cdc} 2$ are independent events. European journal of biochemistry / FEBS. 1995; 230(3):1025-1031.

24. Miyata Y and Nishida E. CK2 controls multiple protein kinases by phosphorylating a kinase-targeting molecular chaperone, Cdc37. Mol Cell Biol. 2004; 24(9):4065-4074.

25. Miyata $Y$ and Nishida E. Supervision of multiple signaling protein kinases by the $\mathrm{CK} 2-\mathrm{Cdc} 37$ couple, a possible novel cancer therapeutic target. Ann N Y Acad Sci. 2004; 1030:150-157.

26. Wang D, Westerheide SD, Hanson JL and Baldwin AS, Jr. Tumor necrosis factor alpha-induced phosphorylation of RelA/p65 on Ser529 is controlled by casein kinase II. J Biol Chem. 2000; 275(42):32592-32597.

27. Jaffe ES. The 2008 WHO classification of lymphomas: implications for clinical practice and translational research. Hematology Am Soc Hematol Educ Program. 2009:523531.
28. Jaffe ES and Pittaluga S. Aggressive B-cell lymphomas: a review of new and old entities in the WHO classification. Hematology Am Soc Hematol Educ Program. 2011; 2011:506-514.

29. Schneider C, Pasqualucci L and Dalla-Favera R. Molecular pathogenesis of diffuse large B-cell lymphoma. Seminars in diagnostic pathology. 2011; 28(2):167-177.

30. Pasqualucci L, Khiabanian H, Fangazio M, Vasishtha M, Messina M, Holmes AB, Ouillette P, Trifonov V, Rossi D, Tabbo F, Ponzoni M, Chadburn A, Murty VV, Bhagat G, Gaidano G, Inghirami G, et al. Genetics of follicular lymphoma transformation. Cell reports. 2014; 6(1):130140.

31. Schmitz R, Young RM, Ceribelli M, Jhavar S, Xiao W, Zhang M, Wright G, Shaffer AL, Hodson DJ, Buras E, Liu X, Powell J, Yang Y, Xu W, Zhao H, Kohlhammer H, et al. Burkitt lymphoma pathogenesis and therapeutic targets from structural and functional genomics. Nature. 2012; 490(7418):116-120.

32. Pierre F, Chua PC, O'Brien SE, Siddiqui-Jain A, Bourbon P, Haddach M, Michaux J, Nagasawa J, Schwaebe MK, Stefan E, Vialettes A, Whitten JP, Chen TK, Darjania L, Stansfield R, Anderes K, et al. Discovery and SAR of 5-(3-chlorophenylamino)benzo[c][2,6]naphthyridine-8-

carboxylic acid (CX-4945), the first clinical stage inhibitor of protein kinase CK2 for the treatment of cancer. J Med Chem. 2011; 54(2):635-654.

33. Trembley JH, Chen Z, Unger G, Slaton J, Kren BT, Van Waes C and Ahmed K. Emergence of protein kinase CK2 as a key target in cancer therapy. Biofactors. 2010; 36(3):187195.

34. Miyata Y. Protein kinase CK2 in health and disease: CK2: the kinase controlling the Hsp90 chaperone machinery. Cell Mol Life Sci. 2009; 66(11-12):1840-1849.

35. Hans CP, Weisenburger DD, Greiner TC, Gascoyne RD, Delabie J, Ott G, Muller-Hermelink HK, Campo E, Braziel RM, Jaffe ES, Pan Z, Farinha P, Smith LM, Falini B, Banham AH, Rosenwald A, et al. Confirmation of the molecular classification of diffuse large B-cell lymphoma by immunohistochemistry using a tissue microarray. Blood. 2004; 103(1):275-282.

36. Fassan M, Pizzi M, Battaglia G, Giacomelli L, Parente P, Bocus P, Ancona E and Rugge M. Programmed cell death 4 (PDCD4) expression during multistep Barrett's carcinogenesis. J Clin Pathol. 2010; 63(8):692-696.

37. Siddiqui-Jain A, Bliesath J, Macalino D, Omori M, Huser N, Streiner N, Ho CB, Anderes K, Proffitt C, O'Brien SE, Lim JK, Von Hoff DD, Ryckman DM, Rice WG and Drygin D. CK2 inhibitor CX-4945 suppresses DNA repair response triggered by DNA-targeted anticancer drugs and augments efficacy: mechanistic rationale for drug combination therapy. Mol Cancer Ther. 2012; 11(4):9941005 . 